\title{
Demonstration of Phylogenetic Relatedness Among Members of the Genus Bifidobacterium by Means of the Enzyme Transaldolase as an Evolutionary Marker
}

\author{
BARBARA SGORBATI ${ }^{1}$ AND JACK LONDON ${ }^{2}$ \\ Istituto di Microbiologia Agraria, Universita di Bologna, Bologna, Italy, ${ }^{1}$ and Laboratory of Microbiology \\ and Immunology, National Institute of Dental Research, Bethesda, Maryland $20205^{2}$
}

\begin{abstract}
Antisera prepared against the purified transaldolases of five species of Bifidobacterium were used to establish natural relationships among the 21 species that presently comprise this genus. The degree of phylogenetic relatedness among the respective members of this genus was estimated from the results of qualitative and quantitative immunological procedures in which the enzymes served as an evolutionary marker. The results are presented in the form of a phylogenetic dendrogram.
\end{abstract}

In a previous immunological study, the enzyme transaldolase (EC 2.2.1.2) was used as an evolutionary reference point to establish natural relationships among 21 species of Bifidobacterium $(10,11)$. With antisera prepared against the transaldolases from $B$. thermophilum, $B$. cuniculi, and $B$. minimum, some degree of immunological homology was demonstrated with the transaldolases of all 21 species. Extensive paired comparisons on immunodiffusion plates indicated that the 21 Bifidobacterium species could be assigned to eight major immunological specificity groups (antigenic groups A through $\mathrm{H}$ ). Quantitative immunological data obtained by microcomplement fixation studies generally supported the divisions within the genus based on immunodiffusion studies, and a dendrogram depicting the natural relationships among the 21 strains was prepared from the composite data (10).

Although the qualitative and quantitative immunological data appeared to be in general accord, it was clear that three specific questions regarding the placement of several species had yet to be resolved. For example, immunodiffusion experiments with the three anti-transaldolase sera relegated $B$. cuniculi and $B$. magnum to the same immunological group, group $C$. However, quantitative immunological data, deoxyribonucleic acid hybridization studies (9), and electrophoretic mobility studies (8) clearly indicated that the two species were different. Similarly, one set of microcomplement fixation data suggested that the transaldolases of $B$. magnum and $B$. suis might be very similar; immunodiffusion data contradicted this finding. Furthermore, these two species, like $B$. cuniculi and $B$. globosum, are found only in animal habitats, yet
$B$. magnum and $B$. suis appeared to be more closely related to human intestinal forms such as $B$. angulatum and $B$. catenulatum. Finally, $B$. adolescentis, which is genetically and phenotypically related to $B$. angulatum and $B$. catenulatum, appears to possess a transaldolase that is more closely related immunologically to those of $B$. longum and $B$. infantis.

The pitfalls of attempting to determine precise natural relationships with too few protein reference points have been adequately discussed in previous publications and need no reiteration here $(2,3)$. Therefore, in an effort to resolve the conflicts in the data described above and to refine further the phylogenetic relationships presented in a preliminary publication of this work (10), antisera were prepared against transaldolases purified from five additional Bifidobacterium species, namely, $B$. infantis, $B$. angulatum, $B$. suis, $B$. globosum, and $B$. asteroides. This paper describes immunological comparisons based on five additional protein reference markers and presents these data in the form of a phylogenetic dendrogram.

\section{MATERIALS AND METHODS}

Bacterial strains. The bacterial strains used in this study, together with their sources and the conditions of cultivation, were described previously (9).

Biochemical procedures. The five-step procedure used to purify the transaldolases of $B$. infantis, $B$. angulatum, $\boldsymbol{B}$. suis, $\boldsymbol{B}$. globosum, and $\boldsymbol{B}$. asteroides to electrophoretic homogeneity was described elsewhere (11). The protein contents of enzyme preparations and cell extracts were determined colorimetrically by the method of Lowry et al. (5).

Immunological procedures. Antisera directed against each of the transaldolases were prepared by administration to pairs of male New Zealand white rabbits of 
four intradermal injections over a period of 4 weeks followed by two intravenous injections at weekly intervals. Intradermal injections contained $0.2 \mathrm{ml}$ of pure transaldolase (roughly $200 \mathrm{IU}$ or between 0.1 and $0.3 \mathrm{mg}$ of protein), $0.2 \mathrm{ml}$ of Freund complete adjuvant, and $0.01 \mathrm{ml}$ of a $1 \%$ solution of methylated bovine serum albumin. Intravenous injections consisted of a solution containing $0.25 \mathrm{ml}$ of transaldolase and $0.01 \mathrm{ml}$ of methylated bovine serum albumin. Levels of transaldolase antibodies were estimated semiquantitatively by the precipitin test (6). Ten days after the final injection, the rabbits were bled and sera were decanted from the clotted blood samples; the sera were stored at $-20^{\circ} \mathrm{C}$ until used.

Immunodiffusion experiments were carried out by the procedure of Stollar and Levine (14). Immune precipitation reactions on Ouchterolony plates were analyzed and interpreted on the basis of the convention of Gasser and Gasser (2). Groups of identical specificity are defined as clusters of transaldolases that produce confluent immune precipitates in doublediffusion experiments when tested against one another with a specific antiserum. Groups of partial identity produce an immune reaction with a single spur that is directed against the lesser of the two antigenically related proteins; double-spurred reactions comprise groups of nonidentity. Microcomplement fixation was performed by the procedure of Wasserman and Levine (14) as modified by Champion et al. $(1,7)$. Antiserum concentrations used with homologous as well as heter- ologous antigens were adjusted to give 75 to $80 \%$ lysis at equivalence. Replicate assays were carried out for each antigen. From the data, the index of dissimilarity was calculated by the equation of Champion et al.:

$$
\text { index of dissimilarity }=\frac{Y H-Y h}{m}+\log \frac{X h}{X H}
$$

where $Y H$ is the percentage of complement fixed with homologous antigen, $Y h$ is the percentage of complement fixed with heterologous antigen, $X H$ is the antiserum dilution used with homologous antigen, $X h$ is the antiserum dilution used with heterologous antigen, and $m$ is the slope of the line obtained when plotting the percentage of complement fixed against the reciprocal of the antiserum dilution $(Y=m \log X+b)$. The immunological distance was obtained by multiplying the $\log$ index of dissimilarity by 100 (1). For the preparation of a dendrogram, immunological distance units were converted to taxonomic distance units by means of the unweighted average linkage program (UPGMA) of Sneath and Sokal (12). Data were processed by use of an ICL model 4130 computer at the University of Leicester, Leicester, Great Britain.

\section{RESULTS AND DISCUSSION}

In an earlier immunodiffusion study (11) in which antisera prepared against the transaldolases of $B$. cuniculi, $B$. thermophilum, and $B$.

TABLE 1. Extent of immunological cross-reactivity of the five anti-transaldolase sera and groups of identical specificity

\begin{tabular}{|c|c|c|c|c|c|c|c|}
\hline \multirow{2}{*}{ Species tested } & \multirow{2}{*}{ Strain } & \multicolumn{5}{|c|}{ Cross-reactions with sera prepared against transaldolases of: } & \multirow{2}{*}{$\begin{array}{l}\text { Specificity } \\
\text { group }\end{array}$} \\
\hline & & B. infantis & B. angulatum & B suis & B. globosum & B. asteroides & \\
\hline B. angulatum & ATCC 27535 & + & + & + & + & + & A \\
\hline B. catenulatum & ATCC 27539 & + & + & + & + & + & A \\
\hline B. dentium & ATCC 27534 & + & + & + & + & + & A \\
\hline B. pseudocatenulatum & ATCC 27917 & + & + & + & + & + & A \\
\hline B. infantis & ATCC 15697 & + & + & + & + & + & B \\
\hline B. adolescentis & ATCC 15705 & + & + & + & + & + & B \\
\hline B. longum & ATCC 15707 & + & + & + & + & + & $\mathrm{B}$ \\
\hline B. breve & ATCC 15698 & + & + & + & + & + & B \\
\hline B. bifidum & ATCC 15696 & + & + & + & + & + & B \\
\hline B. magnum & ATCC 27540 & + & + & + & + & + & $\mathrm{C}$ \\
\hline B. cuniculi & ATCC 27916 & + & + & + & + & + & $\mathrm{C}\left(\mathrm{C}^{\prime}\right)$ \\
\hline B. thermophilum & ATCC 25525 & + & + & + & + & + & D \\
\hline B. boum & ATCC 27917 & + & + & + & + & + & $\mathrm{D}$ \\
\hline B. globosum & ATCC 25864 & + & + & + & + & + & $\mathrm{E}$ \\
\hline B. pseudolongum & ATCC 25526 & + & + & + & + & + & $\mathrm{E}$ \\
\hline B. choerinum & ATCC 27686 & + & + & + & + & + & $\mathrm{E}$ \\
\hline B. minimum & ATCC 27538 & + & + & + & + & + & $\mathrm{F}$ \\
\hline B. subtile & ATCC 27537 & + & + & + & + & + & $\mathrm{F}$ \\
\hline B. suis & ATCC 27533 & + & + & + & + & + & G \\
\hline$B$. indicum & ATCC 25912 & + & + & + & + & + & $\mathrm{H}$ \\
\hline B. asteroides & ATCC 25910 & + & + & + & + & + & $\mathrm{H}$ \\
\hline
\end{tabular}


minimum were used, 21 Bifidobacterium species were assigned to eight antigenic specificity groups (A through $G$ ). With the exception of antigenic group $C$, extensive pairwise crossmatches with the five newly prepared antitransaldolase sera relegated the 21 species to the same specificity groups (Table 1). The antigenic groupings coincide with the arrangement of Bifdobacterium species based on transaldolase electrophoretic mobility rates (10). Antisera prepared against the $B$. globosum and $B$. suis transaldolases produced spurred immune precipitates in Ouchterlony plates when extracts of $B$. cuniculi were compared with $B$. magnum, the enzyme of the former being immunodominant. For this reason, identity group $\mathrm{C}$ was subdivided into $\mathrm{C}$ (containing $B$. cuniculi) and $\mathrm{C}^{\prime}$ (containing $B$. magnum), thereby accommodating the reactions of partial identity observed with the two antisera. It is apparent, however, from their adjacent positions in the hierarchical schemes depicted in Fig. 1c and 1d and from the fact that other antisera cannot distinguish between the two proteins that the two transaldolases are more closely related to each other than to the isofunctional enzymes in the remaining 19 Bifdobacterium species.

Antigenic groups A and B, which are made up solely of human isolates, appeared to be more closely related to each other than to any other groups of identical specificity; like groups $\mathrm{C}$ and $C^{\prime}$, groups $A$ and $B$ were always found in adjacent positions in the five hierarchical schemes shown in Fig. 1. Similarly, the species associated with animal habitats, groups C, D, E, and $\mathrm{G}$, were also found adjacent to one another, although their relative order depended upon the reference protein used to establish the hierarchy. The two species of Bifidobacterium found only in the honey bee, $B$. asteroides and $B$. indicum, comprise antigenic group $\mathrm{H}$ and represent the most antigenically distant members of the genus (Fig. 1).

A complete summary of the microcomplement fixation data obtained with the five newly prepared antisera, as well as those obtained with the three original anti-transaldolase sera, is presented in Table 2 . It is immediately apparent from these data that the degree of immunological dissimilarity within identical specificity groups $\mathrm{A}, \mathrm{B}$, and $\mathrm{C}$ was extensive. Transaldolases found in the species pairs of $B$. thermophilus $-B$. boum, B. globosum-B. psuedolongum, B. minimum-B. subtile, $B$. asteroides $-B$. indicum, and $B$. infantis- $B$. longum exhibited a substantial degree of antigenic homology. However, the immunological distances separating the respective species in groups $\mathrm{A}, \mathrm{B}$, and $\mathrm{C}$ were of roughly the same magnitude as anti-fructose diphosphate aldolase immunological distances in a comparison of species of group D streptococci (3), the Lactobacillus casei group (3), and a group of Pediococcus species (4).

Differences among Bifidobacterium groups C, $\mathrm{D}, \mathrm{E}, \mathrm{F}$, and $\mathrm{G}$ were even more dramatic, ranging from a small immunological distance of 130 to a distance of over 200 . These relatively high values contrast sharply with the more gradual succession of immunological distance values noted among groups of identical specificity in the genera Streptococcus and Lactobacillus (3). It is not surprising, therefore, that precise correlations between the ordering of the numerical immunological distance values (Table 2) and the corresponding order of antigenic specificity groups (Fig. 1) were not seen beyond the second or third cluster of either grouping. However, differences in the respective orderings rarely exceeded a single position shift in any of the five schemes. Only those transaldolases belonging to identical specificity groups $\mathrm{A}$ and $\mathrm{B}$ exhibited a rough gradation of immunological distances when surveyed with anti-transaldolase sera from $B$. angulatum and $B$. infantis. From the values presented in Table 2 , the $B$. adolescentis transaldolase may form a natural bridge between the group A and B bifidobacteria. Of the group B species, it was the least related to the $B$. infantis reference enzyme and it exhibited the greatest similarity to the group A reference enzyme (Fig. 1 ). The remaining six groups of identical specificity are remarkable in that they appeared to be immunologically isolated from one another.

The relationships within and among the various antigenic groups are graphically depicted in the dendrogram shown in Fig. 2. Those species exhibiting extensive structural homology among their transaldolases (as ascertained from their positions in the dendrogram) also shared a significant degree of deoxyribonucleic acid homology. For example, the extent of deoxyribonucleic acid homology observed between members within each of the species pairs mentioned earlier, as well as between $B$. asteroides and $B$. indicum, was $50 \%$ or greater. The dendrogram also shows that the various species were related according to their natural habitats. The uppermost clusters contain all nine species isolated from human sources. This group is followed by three clusters of seven species associated mainly with animals. Finally, the species isolated from sewage and insects form two small, but distinct, clusters. These data are important because they provide a line of evidence linking evolutionary divergence in procaryotes to changes in their ecological niches. Although it is not possible to determine whether insects or warm-blooded animals were the original habitat for the bifidobacteria, it is clear that their dissemination to other environments was accompanied by an extensive 
a.

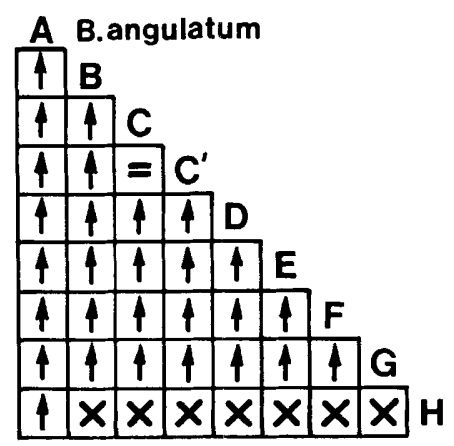

B. angulatum $A: A>B>C=C>D>E>F>G / H$

C. E B.globosum

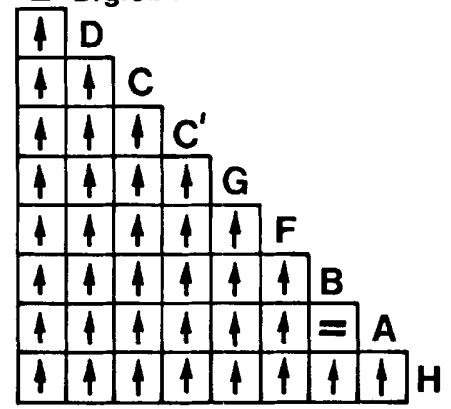

B.globosum $E$ : $E>D>C>C^{\prime}>G>F>B=A>H$ b. B B. infantis

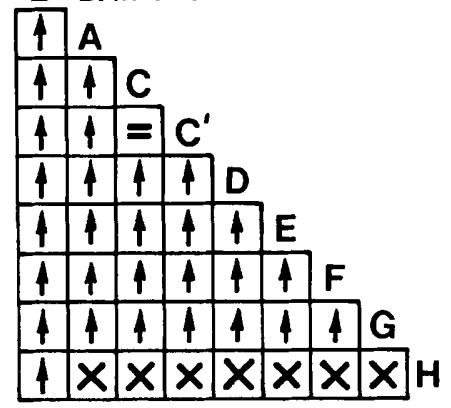

B. infantis $B: B>A>C=C^{\prime}>D>E>F>G / H$

d.

G B. suis

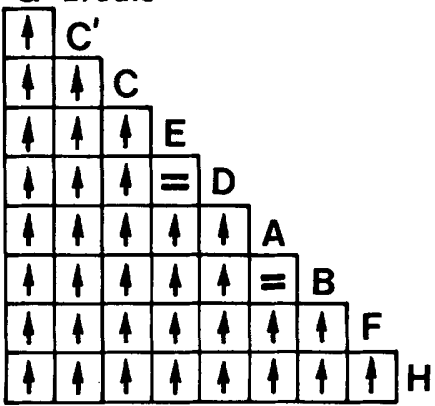

B. suis $G$ : $G>C^{\prime}>C>E=D>A=B>F>H$

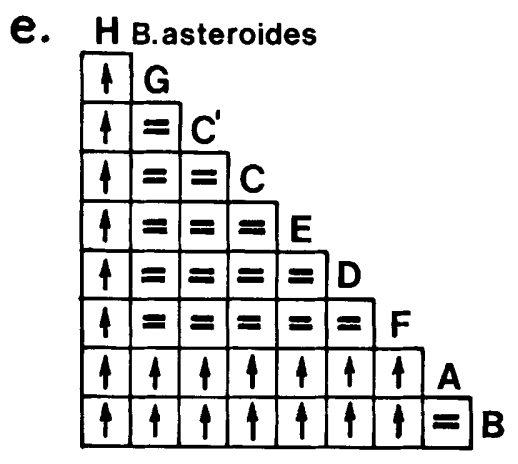

B. asteroides $H: H>G=C^{\prime}=C=E=D=F>A=B$

FIG. 1. Hierarchical ordering of the 21 Bifidobacterium species as determined by immunodiffusion experiments with the five anti-transaldolase sera. The uppercase letters denote the groups of antigenic specificity referred to in Table 1; transaldolases from species within each group invariably produced confluent precipitates (reactions of identical specificity) when tested against one another on Ouchterlony plates regardless of the antiserum used. The only exception to these observations occurred in group $\mathrm{C}$, which could be subdivided with two antisera. The species cited at the uppermost section of each of the five hierarchical summaries was the source of the transaldolase against which the antiserum used in that set of immunodiffusion experiments was prepared. The arrow indicates the immunodominant antigens in the crossmatch, an equal sign is indicative of confluent precipitates or a reaction of identity, and the $\times$ signifies the production of double spurs or a reaction of nonidentity. A summary of the descending order of relatedness is presented beneath each hierarchy. 
TABLE 2. Immunological distance values for transaldolases of 21 species of bifidobacteria

\begin{tabular}{|c|c|c|c|c|c|c|c|c|c|}
\hline \multirow[b]{2}{*}{ Nomenspecies } & \multicolumn{9}{|c|}{ Immunological distances with antisera prepared against transaldolases of: } \\
\hline & $\begin{array}{l}\text { Speci- } \\
\text { ficity } \\
\text { group }\end{array}$ & \begin{tabular}{|c|} 
B. angu- \\
latum \\
ATCC \\
27535
\end{tabular} & $\begin{array}{c}\text { B. infantis } \\
\text { ATCC } \\
27920\end{array}$ & $\begin{array}{l}\text { B. cuniculi } \\
\text { ATCC } \\
27916^{a}\end{array}$ & $\begin{array}{c}\text { B. thermo- } \\
\text { philum } \\
\text { ATCC } \\
25866^{\circ}\end{array}$ & $\begin{array}{l}\text { B. globosum } \\
\text { ATCC } \\
25864\end{array}$ & $\begin{array}{l}\text { B. "minimum" } \\
\text { ATCC } \\
27528^{a}\end{array}$ & $\begin{array}{l}\text { B. suis } \\
\text { ATCC } \\
27533\end{array}$ & $\begin{array}{c}\text { B. aster- } \\
\text { oides } \\
\text { ATCC } \\
25910\end{array}$ \\
\hline B. angulatum & A & 0 & 120 & 174 & 177 & 165 & 182 & 185 & 194 \\
\hline B. catenulatum & A & 72 & 123 & 177 & 175 & 165 & 183 & 187 & 195 \\
\hline B. dentium & A & 81 & 141 & 188 & 174 & 167 & 180 & 190 & 197 \\
\hline $\begin{array}{l}\text { B. pseudocatenu- } \\
\text { latum }\end{array}$ & A & 73 & 130 & 177 & 175 & 163 & 179 & 189 & 195 \\
\hline B. infantis & B & 109 & 0 & 199 & 160 & 174 & 202 & 177 & 208 \\
\hline B. adolescentis & B & 84 & 117 & 191 & 167 & 172 & 199 & 183 & 199 \\
\hline B. longum & B & 107 & 36 & 197 & 163 & 174 & 203 & 178 & 207 \\
\hline B. breve & B & 89 & 77 & 196 & 153 & 177 & 204 & 181 & 204 \\
\hline B. bifidum & B & 106 & 76 & 197 & 169 & 169 & 202 & 183 & 206 \\
\hline B. cuniculi & C & 154 & 174 & 0 & 146 & 130 & 175 & 169 & 189 \\
\hline B. magnum & $\mathrm{C}^{\prime}$ & 169 & 183 & 120 & 184 & 150 & 195 & 160 & 165 \\
\hline B. thermophilum & D & 188 & 154 & 161 & 0 & 136 & 167 & 162 & 185 \\
\hline B. boum & D & 188 & 157 & 161 & 32 & 144 & 160 & 164 & 187 \\
\hline B. globosum & E & 160 & 176 & 132 & 138 & 0 & 171 & 169 & 176 \\
\hline B. pseudolongum & $\mathrm{E}$ & 162 & 177 & 136 & 143 & 51 & 170 & 171 & 177 \\
\hline B. "minimum" & $\mathrm{F}$ & 190 & 195 & 150 & 181 & 181 & 0 & 196 & 190 \\
\hline B. "subtile" & $\mathrm{F}$ & 194 & 196 & 154 & 183 & 183 & 47 & 199 & 190 \\
\hline B. suis & G & 172 & 184 & 157 & 154 & 160 & 194 & 0 & 160 \\
\hline B. asteroides & $\mathrm{H}$ & 211 & 202 & $\mathrm{NR}^{b}$ & 214 & 187 & 189 & 174 & 0 \\
\hline B. indicum & $\mathbf{H}$ & 214 & 206 & NR & 207 & 188 & 189 & 176 & 46 \\
\hline
\end{tabular}

a Taken from reference 10 .

${ }^{b}$ Not reported.

TAXONOMIC DISTANCE

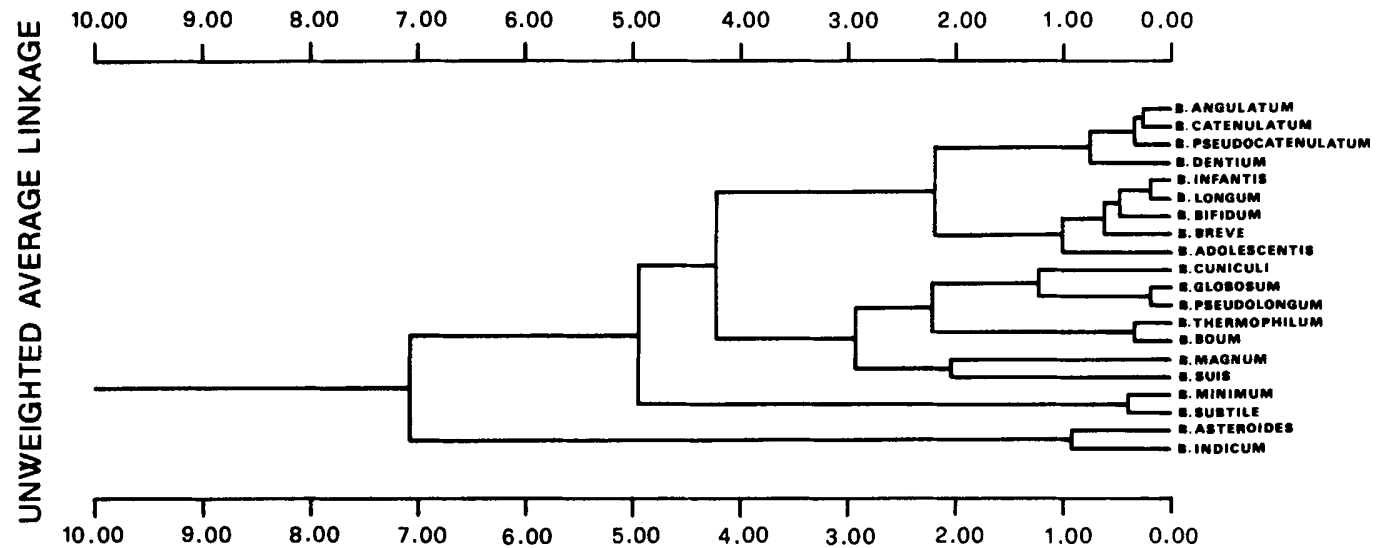

FIG. 2. Evolutionary relationships among the bifidobacteria as estimated from the immunological distances obtained with eight respective anti-transaldolase sera. Data for the preparation of the dendrogram were derived from Table 2. 
molecular diversification, as evidenced by the relatively substantial degree of antigenic dissimilarity noted among their transaldolases.

The segregation of the 21 species of bifidobacteria into four quite distinct and apparently natural clusters suggests that a subdivision of the genus into four subgenera would more accurately reflect the group's natural history. $\mathrm{Al}$ though no formal proposal is being promulgated at this time, such action could be justified on the basis of the transaldolase studies reported here, the deoxyribonucleic acid hydridization studies (9), and the segregation of the 21 species according to their natural habitats.

\section{REPRINT REQUESTS}

Address reprint requests to: Dr. Barbara Sgorbati, Istituto di Microbiologia Agraria, Universita di Bologna, Bologna, Italia.

\section{LITERATURE CITED}

1. Champion, A. B., E. M. Prager, D. Wachter, and A. C Wilson. 1974. Microcomplement fixation, p. 397-416. In C. A. Wright (ed), Biochemical and immunological taxonomy of plant and animals. Academic Press, Inc., London.

2. Gasser, F., and C. Gasser. 1971. Imımunological relations among lactic acid dehydrogenases in the genera Lactobacillus and Leuconostoc. J. Bacteriol. 106:113-125.

3. London, J., and K. Kline. 1973. Aldolases of lactic acid bacteria: a case history in the use of an enzyme as an evolutionary marker. Bacteriol. Rev. 37:453-478.
4. London, J., and N. M. Chace. 1976. Aldolases of the lactic acid bacteria. Arch. Microbiol. 110:121-128.

5. Lowry, O. H., N. J. Rosebrough, A. L. Farr, and R. J. Randall. 1951. Protein measurement with the Folin phenol reagent. J. Biol. Chem. 193:265-275.

6. Perrin, D. 1963. Immunological studies with genetically altered $\beta$-galactosidases. Ann. N.Y. Acad. Sci. 103:10581066.

7. Prager, E. M., and A. C. Wilson. 1971. The dependence of immunological cross-reactivity upon sequence resemblance among lysozymes. I. Microcomplement fixation studies. J. Biol. Chem. 246:5978-5989.

8. Scardovi, V., and B. Sgorbati. 1974. Electrophoretic types of transaldolase, transketolase and other enzymes in bifidobacteria. Antonie van Leeuwenhoek J. Microbiol. Serol. 40:427-440.

9. Scardovi, V., L. D. Trovatelli, G. Zani, F. Crociani, and D. Matteuzzi. 1971. Deoxyribonucleic acid homology relationships among species of the genus Bifidobacterium. Int. J. Syst. Bacteriol. 21:276-204.

10. Sgorbati, B. 1979. Preliminary quantification of immunological relationships among the transaldolases of the genus Bifidobacterium. Antonie van Leeuwenhoek J. Microbiol. Serol. 45:557-564.

11. Sgorbati, B., and V. Scardovi. 1979. Immunological relationships among transaldolases in the genus Bifidobacterium. Antonie van Leeuwenhoek J. Microbiol. Serol. 45:129-140.

12. Sneath, P. H. A., and R. Sokal. 1973. Numerical taxonomy. The principles and practice of numerical classification. W. H. Freeman, San Francisco.

13. Stollar, D., and L. Levine. 1963. Two dimensional immunodiffusion. Methods Enzymol. 6:848-854.

14. Wasserman, E., and L. Levine. 1961. Quantitative microcomplement fixation and its rise in the study of antigenic structure by specific antigen-antibody inhibition. J. Immunol. 87:290-295. 